\title{
RELATIONSHIP BETWEEN CARDIORESPIRATORY FITNESS AND BLOOD PRESSURE OF NIGERIAN ADOLESCENTS.
}

\author{
Journal website at; \\ http://mrtbjournal.org/index.php/njme/issue/current/showToc \\ *AO AKINPELU, **OO OYEWOLE, ***KS ORITOGUN
$1 *$ Department of Physiotherapy, College of Medicine, University of Ibadan, Ibadan. \\ **Department of Physiotherapy, Olabisi Onabanjo University Teaching Hospital, Sagamu, Ogun State. \\ **:*Department of Medical Microbiology and Parasitology (Biostatistics Unit), \\ Olabisi Onabanjo University, Sagamu.
}

Correspondence to:

Oo Oyewole

\section{SUMMARY}

Background: Knowledge about the relationship between cardiorespiratory fitness and health outcome is important, because such information adds essential information to the aggregated data that serve as the basis for physical activity guidelines.

Objective: The purpose of this study was to evaluate relationship between cardiorespiratory fitness and blood pressure in normotensive individual.

Methods: A cross-sectional survey of secondary school students in Sagamu local government area of Ogun state, Nigeria during 2006 school year was carried out. In all 1638 (790 male and 848 female) apparently healthy students with age ranged between 12 and 18 years were selected from 11 schools ( 8 public and 3 private). The Cardiorespiratory fitness (CRF) and blood pressure of the subjects were measured.

Results: A significant negative correlation between CRF and blood pressure (systolic and diastolic) was observed. There was significant curvilinear graded relation between $\mathrm{CRF}$ and blood pressure. Coefficient of determination $\left(\mathrm{R}^{2}\right)$ for cardiorespiratory fitness was $1.54 \%$ and $1.18 \%$ for systolic and diastolic blood pressure respectively.

Conclusion: The greatest benefit may be achieved when increasing the fitness from low to moderate cardiorespiratory fitness. It is therefore important to direct action towards those adolescents who are the least physically fit to increase their cardiorespiratory fitness and hence reduced their blood pressure.

Key words: Cardiorespiratory fitness index, blood pressure, CHD

\section{INTRODUCTION}

Cardiorespiratory fitness (CRF) and blood pressure are both related to health, and their interrelation to each other has been documented but with little information on Nigeria population. The effects of high CRF include lower risk of all-cause mortality and cardiovascular disease (CVD) mortality among both hypertensive and normotensive individual with the metabolic syndrome (Evenson et al, 2004; Katzmarzyk et al, 2004; LaMonte et al, 2005). It also provides protection against cancer mortality in men (Oliveria et al, 1996; Lee and Blair, 2002a), and reduced risk factor for functional decline independent of disease processes (Morey et al, 1998). Other studies have shown an inverse relation between fitness level and incidence of coronary heart disease (CHD) as well as number of risk factors for CHD (Laukkanen et al, 2001; Church et al, 2002; Lee and Blair, 2002b; Kurl et al, 2003; Carnethon et al, 2005; Church et al, 2005; William et al, 2005). Early promotion of physical fitness and activity in children has been considered an optimal strategy for preventing these lifelong diseases.

Hypertension is a major risk factor for stroke, coronary heart disease, and congestive heart failure (Stokes et al, 1989). The clinical symptoms of many chronic diseases do not become apparent until late in life, but it is generally accepted that the origin of many diseases and conditions such as hypertension lies in early life (KlassonHeggebø et al, 2006). The aetiology of such diseases is of course multifactorial, but cardiorespiratory fitness may play an important role. The association between cardiorespiratory fitness and hypertension is documented in the adult population, showing that people with low 
fitness have increased risk of hypertension (Blair et al, 1984; Sui et al, 2007). The pattern and strength of association between fitness and hypertension persisted in analyses stratified on body mass index, age, and the presence of prehypertension at baseline (Barlow et al, 2006). Reporting on 3,350 middle-aged Japanese men, Sawada et al (1993) observed a 90 percent higher 5-year age- and covariate-adjusted incidence of hypertension for men in the lowest compared with the highest quintile of fitness estimated from submaximal cycle ergometry. Carnethon et al (2003) reported that, after adjustment for age, sex, and other confounding factors, each 1-minute decrease in maximal treadmill performance was associated with a 19 percent higher 15-yearrisk of incident hypertension among men and women. In children and adolescents, an association between cardiorespiratory fitness and blood pressure has been observed (Andersen, 1994; Boreham, 1997; Ewart, 1998; Nielsen and Andersen, 2003). However, studies analyzing the graded relation between cardiorespiratory fitness and blood pressure in this population are scarce.

Knowledge about the relationship between cardiorespiratory fitness and health outcome is important, because such information adds essential information to the aggregated data that serve as the basis for physical activity guidelines (Biddle et al, 1999). Therefore, the purpose of this study was to evaluate relationship between cardiorespiratory fitness and blood pressure in normotensive adolescent.

\section{MATERIALSANDMETHODS}

Subjects: A cross-sectional survey of secondary school students in Sagamu local government area of Ogun state, Nigeria during 2006 school year was carried out. There were 31 secondary schools in the area, 16 public and 15 private schools. The sample of 11 schools (8public and 3 private) was drawn by stratifying the school into public and private schools and randomly selecting schools with probability proportional to size. The sample of schools was drawn by the help of zonal education authority in the area. Participants were drawn from the selected schools. In all 1638 (790 male and 848 female) apparently healthy students were selected. Their age ranged between 12 and $18(14.96 \pm 1.84)$ years.

\section{Procedure}

Ethical approval was sought and obtained from the Institutional Review Committee of University of Ibadan and University College Hospital, Ibadan. Informed consent was sought from the participants and their parents; permission was sought from local education authority and the principals of the selected schools. The nature, purpose and procedure of the study were explained to the participants in detail. The biodata of each participant was taken: this included age (as at last birth day) and sex. Each of the participants was medically screened for any disability and pathology.

\section{Measurements}

Cardiorespiratory fitness: Cardiorespiratory fitness index was calculated using 3-minute step test. The participant was dressed in suitable clothes and the procedure was explained and demonstrated. The participant stepped up and down the step at a pace of 24 steps per minute (Verducci, 1980). The stepping was done in four counts: 1 up with one foot; 2 up with the second foot, body erect, legs straight on the bench; 3 down with the foot placed on the bench first and 4 down with the other foot (Verducci, 1980). A metronome set at 96 beats per minute was used to establish the rate of 24 steps a minute. The stepping test lasted for 3 minutes unless the participant must stop sooner because of exhaustion or failed to maintain pace with the metronome. The duration of stepping test was recorded in seconds. Immediately after completing the stepping test, the participant sat quietly on a chair. The pulse rate of radial artery was counted 1 to $1 \frac{1}{2}, 2$ to $2 \frac{1}{2}$ and 3 to $3 \frac{1}{2}$ minutes after stepping ceases. The Cardiorespiratory fitness index (CRFI) was computed with the following formula:

CRFI $=$ Duration of exercise in second X 100

$2 \mathrm{X}$ sum of pulse counts in recovery

(Amusa and udoh, 1982).

Blood Pressure: Blood pressure (SBP and DBP) was measured according to American Heart Association guidelines using an aneroid sphygmomanometer (Frank Industries Inc., 9643 Great Smoky Drive, Vacon Rouge LA 70814, USA) and a cuff suitable to the subject's arm circumference. Trained personnel and researcher measured blood pressure after 5 minutes of rest in the sitting position (Grotto et al, 2006).

\section{Data Analysis}

Statistical analysis was carried out using statistical software package SPSS version 15.0. Descriptive statistics of mean and standard deviation were used to examine the data. Pearson moment correlation was used to find correlation between cardiorespiratory fitness and blood pressure. Regression analysis was also carried out to see relationship between the variables. The graded relation between CRF and blood pressure were analyzed using excel package models. P-value $<0.05$ was considered to be statistically significant.

\section{RESULTS}

A total of 1638 secondary school children participated in this study. They comprised $790(48.2 \%)$ males and $848(51.8 \%)$ females. One thousand four hundred and twelve (1412) were from 8 public secondary schools and 226 from 3 private secondary schools in Sagamu local government area of Ogun State, Nigeria.

Table 1 presents descriptive variables of the study population. The boys were significantly older than the girls. Table 2 shows correlation matrix between cardiorespiratory fitness and blood pressure (systolic and 
diastolic). There was significant negative correlation between cardiorespiratory fitness and blood pressure (systolic and diastolic respectively) except for females' diastolic which was not significant. There was also significant strong correlation between systolic and diastolic blood pressure.

Figures 1 and 2 show the relation between cardiorespiratory fitness and systolic and diastolic blood pressure respectively. The systolic blood pressure showed a significant curvilinear ( $3^{\text {rd }}$ degree polynomial) relation with cardiorespiratory fitness. The regiession equation was $y=0.0001 x^{3}-0.0191 x^{2}+0.6035 x+85.028$. Cardiorespiratory fitness explained $1.54 \%$ of total variance. The diastolic blood pressure also showed a significant curvilinear ( $3^{\text {rd }}$ degree polynomial) relation with cardiorespiratory fitness. The regression equation was $y=0.0001 x^{3}-0.0183 x^{2}+0.8562 x+39.13$. The percentage contribution to the total variance from cardiorespiratory fitness was $1.18 \%$.

Table I: Descriptive Statistics by Gender

\begin{tabular}{llll}
\hline Variables & $\begin{array}{l}\text { Male } \\
(\mathbf{n = 7 9 0 )} \\
\text { Mean(SD) }\end{array}$ & $\begin{array}{l}\text { Female } \\
(\mathbf{n = 8 4 8}) \\
\text { Mean(SD }\end{array}$ & $\mathrm{p}$ \\
\hline $\begin{array}{l}\text { Age(years) } \\
\begin{array}{l}\text { Systolic BP } \\
\text { (mmHg) }\end{array}\end{array}$ & $15.1(1.9)$ & $14.8(1.8)$ & .001 \\
$\begin{array}{l}\text { Diastolic BP } \\
\text { (mmHg) }\end{array}$ & $81.3(14.8)$ & $81.5(13.8)$ & .718 \\
CRF & $48.4(9.6)$ & $48.5(9.3)$ & .899 \\
\hline
\end{tabular}

Key: $\mathrm{BP}=$ blood pressure

$\mathrm{CRF}=$ Cardiorespiratory Fitness

Table 2: Correlation Matrix between Cardiorespiratory Fitness and Blood Pressure

\begin{tabular}{cll}
\hline Variables & SBP & DBP \\
\hline CRF Male & $-.096^{* *}$ & $-.104^{* *}$ \\
Female & $-.073^{*}$ & -.056 \\
All & $-.083^{* *}$ & $-.075^{* *}$ \\
DBP Male & $.724^{* *}$ & \\
Female & $.695^{* *}$ & \\
All & $.709^{* *}$ & \\
\hline
\end{tabular}

Key: $\mathrm{SBP}=$ systolic blood pressure, $\mathrm{DBP}=$ diastolic blood pressure

$\mathrm{CRF}=$ Cardiorespiratory Fitness

${ }^{* *}$ Correlation is significant at the .01 level (2-tailed)

* Correlation is significant at the .05 level (2-tailed)

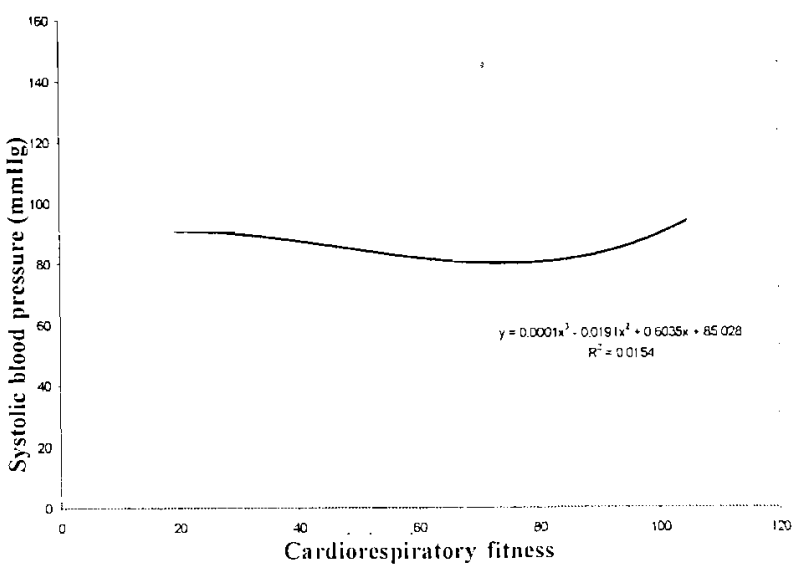

Fig. I: Graded relation between Systolic blood pressure and cardiorespiratory fitness.

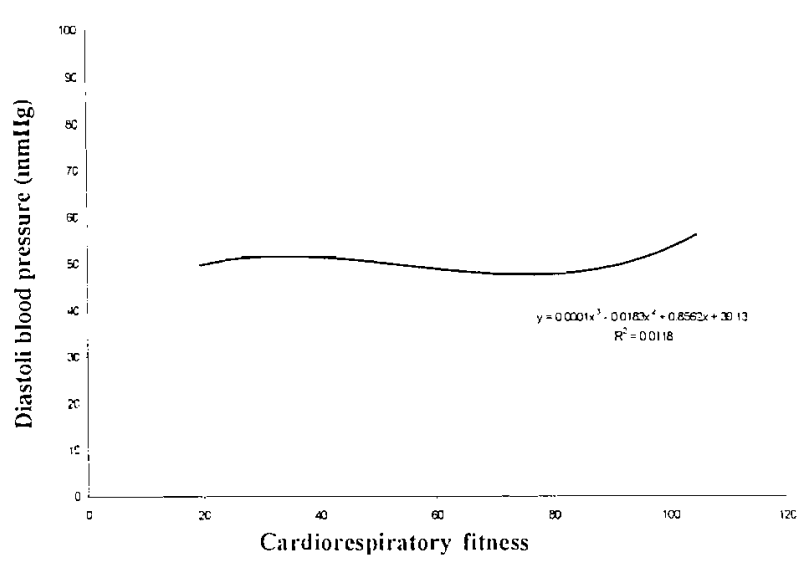

Fig. 2: Graded relation between diastolic blood pressure and cardiorespiratory fitness.

\section{DISCUSSION}

This study evaluated the relationship and graded associations between cardiorespiratory fitness and blood pressure. The results show a graded relation between cardiorespiratory fitness and blood pressure (systolic and diastolic); the relation was curvilinear in the whole population. The third degree term of the fitness variable, which could indicate a more complex association than a second order polynomial, was significant for both systolic and diastolic blood pressure and only explained $1.54 \%$ and $1.18 \%$ of the total variation in systolic and diastolic blood pressure respectively. This observation was similar to the study of Klasson-Heggebo et al, (2006). Systolic and diastolic blood pressure were significantly related to cardiorespiratory fitness, with a somewhat weaker association for diastolic than systolic blood pressure. These results are in accordance with those of Hansen et al, (1990); Andersen (1994); Boreham et al (2001); KlassonHeggebø et al (2006) and Koley (2007). The association was weak, but may be clinically relevant.

Epidemiological studies report that physical activity and/or fitness are effective at reducing arterial blood pressure among hypertensive adults; however, it is not clear if these benefits can also be observed in children (Thomas et al, 2003). In this study, the association between 
CRF and arterial blood pressure was confirmed, which is supported by previous studies (Shea et al, 1994 and Klassan-Heggebo, 2006). Nevertheless, other studies have reported contrasting results (Jenner et al, 1992 and Rodrigues et al, 2007). It is believed that the contradictory result may be due to methodological differences and the diversity of factors that affect blood pressure. Such factors include physical activity, mental activity, age, sex, BMI etc (HitendrasinhG et.al, 2004; Rodrigues et al, 2007). Furthermore, there is great variety in the methods employed in clinical investigations to identify CRF, such as direct and indirect measurements of VO2máx and recovery heart rate which can cause results to diverge between studies.

The cardioprotection of higher CRF was observed across a broad range of elevated blood pressures in the study of Sui et al (2007). In men with stage 2 hypertension (HTN), CVD incidence rates in moderately and highly fit men were $17 \%$ and $35 \%$ lower, respectively, than those in low fit men. Similarly, lower event rates of $29 \%$ to $41 \%$ and $57 \%$ to $65 \%$ were seen in moderately and highly fit men, respectively, with controlled HTN and with stage 1 HTN. Women with moderate and high CRF experienced CVD rates that were $14 \%$ to $75 \%$ lower than those in women with low CRF who had controlled, stage 1, or stage 2 HTN. Hansen et al, 1991 also showed the effectiveness of physical training in lowering blood pressure and increasing physical fitness among population of children. This study and others suggest the need for adolescents to be involved in physical activities to improve their CRF and thereby lowering their blood pressure, because it had been shown that certain cardiovascular adaptations with fitness training which cause lower blood pressure do exist. The stroke volume increases with lower heart rate, there by increased capillarization of muscles and greater extraction of oxygen from the arteries (Koley, 2007).

\section{CONCLUSION}

In this study a curvilinear ( $3^{\text {rd }}$ order polynomial) relation was found between cardiorespiratory fitness and blood pressure. Therefore the greatest benefit may be achieved when increasing the fitness from low to moderate. It is therefore important to direct action towards those adolescents who are the least physically fit.

\section{REFERENCES}

- Amusa LO and Udoh CO (1982): Dynamics of Physical Fitness. Osogbo. Adebara Publishers, page $1-17$.

- Andersen LB (1994). Blood pressure, physical fitness and physical activity in 17-yearold Danish adolescents. Journal of Internal Medicine 236: 323-30.

- Barlow CE, Lamonte MJ, Fitzgerald SJ, Kampert JB, Perrin JL and Blair SN (2006): Cardiorespiratory fitness is an independent predictor of hypertension incidence among initially normotensive healthy women. American Journal of Epidemiology 163(2): 142 - 50 .

(2) Biddle S, Sallis JF and Cavill NA, (eds) 1999: Young and active? Young people and health enhancing physical activity: evidence and implications. London: Health Education Authority, 1998. Page1-149.

- Blair SN, Goodyear NN, Gibbons LW and Cooper KH (1984): Physical fitness and incidence of hypertension in healthy normotensive men and women. Journal of the American Medical Association 252: 487-90.

- Boreham C, Twisk J, Murray L, Savage M, Strain JJ and Cran G (2001): Fitness, fatness, and coronary heart disease risk in adolescents: the Northern Ireland Young Hearts Project. Medicine and Science in Sports and Exercise 33: $270-4$.

- Boreham CA, Twisk J, Savage MJ, Cran GW and Strain JJ (1997): Physical activity, sports participation, and risk factors in adolescents. Medicine and Science in Sports and Exercise 29: 788-93.

- Carnethon MR, Gulati M and Greenland P (2005): Prevalence and cardiovascular disease correlates of low cardiorespiratory fitness in adolescents and adults. Journal of the American Medical Association 294(23): 2981-8.

- Carnethon MR, Gidding SS, Nehgme R, Sidney S, Jacobs DR Jrand Liu K (2003): Cardiorespiratory fitness in young adulthood and the development of cardiovascular disease risk factors. Journal of the American Medical Association 290:3092-100.

- Church TS, Barlow CE, Earnest CP, Kampert JB, Priest EL. and Blair S.N (2002): Association between cardiorespiratory fitness and C-reactive protein in men. Arteriosclererosis, Thrombosis and Vascular Biology 22(11): 1869-76.

- Church TS, LaMonte MJ, Barlow CE and Blair SN (2005): Cardiorespiratory fitness and body mass index as predictor of cardiovascular disease mortality among men with diabetes. Archives of Internal Medicine 165(18): 2114-20.

- Evenson KR, Stevens J, Thomas R and Cai J (2004): Effect of cardiorespiratory fitness on mortality among hypertensive and normotensive women and men. Epidemiology 15(5): 565-72.

- Ewart CK, Young DR and Hagberg JM (1998): Effects of school-based aerobic exercise on blood pressure in adolescent girls at risk for hypertension. American Journal of Public Health 88(6): 949-951.

- Grotto I, Grossman E, Huerta M and Sharabi Y (2006) Prevalence of prehypertension and associated cardiovascular risk profiles among young Israeli adults. Hypertension 48(2): 254.

- Hansen H.S, Froberg K, Hyldebrandt N and Nielsen J.R (1991): A controlled study of eight months of physical training and reduction of blood pressure in children: the Odense schoolchild study. British Medical Journal 303(6804): 682-685.

- Hansen HS, Hyldebrandt N, Froberg K and Nielsen J.R (1990): Blood pressure and physical fitness in a population of children: the Odense Schoolchild Study. Joumal of Human Hypertension 4:615-20.

๑) Hitendrasinh GT, Predeep K and VikasK D (2004): Effect of physical and mentai activity on blood pressure. Indian Jounal of Pediairics $7:(4): 307-312$. 
- Jenner DA, Vandongen R and Beilin LJ (1992): Relationships between blood pressure and measures of dietary energy intake, physical fitness, and physical activity in Australian children aged 11-12 years. Journal of Epidemiology and Community Health 46:108-13.

- Katzmarzyk PT, Church TS and Blair SN (2004): Cardiorespiratory fitness attenuates the effects of the metabolic syndrome on all-cause and cardiovascular disease mortality in men. Archives of Internal Medicine 164(10): 1092-7.

- Klasson-Heggebø L, Andersen LB, Wennlo“f AH, Sardinha I... Harro M, Froberg K. and Anderssen SA (2006): Graded iations between cardiorespiratory fitness, fatness, and 1. wd pressure in children and adolescents British Joumal of Sports Medicine 40:25-29.

- Koley S (2007): Association of Cardio respiratory Fitness, Body Composition and Blood Pressure in Collegiate Population of Amritsar, Punjab, India. The Internet Journal of Biological Anthropology. Volume 1 Number 1.

- Kurl S, Laukkanen JA, Rauramaa R, Lakka TA, Sivenius J and Salonen JT (2003): Cardiorespiratory fitness and the risk for stroke in men. Archives of Internal Medicine 163(14): 1682-8.

- LaMonte MJ, Barlow CE, Jurca R, Kampert JB, Church TS and Blair SN (2005): Cardiorespiratory fitness is inversely associated with the incidence of metabolic syndrome: a prospective study of men and women. Circulation 112(4): 505-12.

- Laukkanen JA, Lakka TA, Rauramaa R, Kuhanen R, Venalainen JM, Salonen R and Salonen JT (2001): Cardiovascular fitness as a predictor of mortality in men. Archives of Internal Medicine 161: 825-831

- Lee CD and Blair SN (2002a): Cardiorespiratory fitness and smoking-related and total cancer mortality in men. Medicine and Science in Sports and Exercise 34(5): 735-9.

- Lee CD and Blair SN (2002b): Cardiorespiratory fitness and stroke mortality in men. Medicine and Science in Sports and Exercise 34(4): 592-5.

- Morey MC, Pieper CF and Carnoni-Huntley J (1998): Physical fitness and functional limitation in communitydwelling older adults. Medicine and Science in Sports and Exercise 30(5): 715-23.
- Nielsen GA and Andersen LB (2003): The association between high blood pressure, physical fitness, and body mass index. Preventive Medicine 36: 229-34.

- Oliveria SA, Kohl HW $3^{\text {rd }}$, Trichopovlos D and Blair S.N (1996): The association between cardiorespiratory fitness and prostate cancer. Medicine and Science in Sports and Exercise 28(1): 97-104.

- Rodrigues AN, Perez AJ, Carletti L, Bissoli NS and Abreu GR (2007): The association between cardiorespiratory fitness and cardiovascular risk in adolescents. Jornal de Pediatria 83(5): $429-435$.

- Sawada S, Tanaka H, Funakoshi M, Shindo M, Kono S and Ishiko T (1993): Five year prospective study on blood pressure and maximal oxygen uptake. Clinical and Experimental Pharmacology and Physiology 20: 483-7.

- Shea S, Basch CE, Gutin B, Stein AD, Contento IR, Irigoyen $M$ and Zybert $P$ (1994): The rate of increase in blood pressure in children 5 years of age is related to changes in aerobic fitness and body mass index. Pediatrics 94(4 Pt 1): $465-70$.

- Stokes J, Kannel WB, Wolf PA, D'Agostino RB and Cupples LA (1989). Blood pressure as a risk factor for cardiovascular disease. The Framingham Study: 30 years of follow-up. Hypertension 13: 13-18.

- Sui X, LaMonte MJ and Blair SN (2007): Cardiorespiratory fitness and risk of nonfatal cardiovascular disease in women and men with hypertension. American Journal of Hypertension 20(6): $608-15$.

- Thomas NE, Baker JS and Davies B (2003): Established and recently identified coronary heart disease risk factors in young people: the influence of physical activity and physical fitness. Sports Medicine 33: 633 - 50.

- Verducci FM (1980): Measurement concepts in physical education. The C.V Mosly Company, St. Louis, Toronto. London.

- Willet W (1990): Nutritional Epidemiology. Oxford, Oxford University Press Inc. $217-219$.

- William MJ, Milne BJ, Hanvox RJ and Poulton R (2005): $\mathrm{C}$-reactive protein and cardiorespiratory fitness in young adults. European Journal of Cardiovascular Prevention and Rehabilitation 12(3): 216-20. 